\title{
The Modified International Standard Classification of Occupations defined by the clustering of occupational characteristics in the Korean Working Conditions Survey
}

\author{
Soo Beom CHOI ${ }^{1,2}$, Jin-Ha YOON ${ }^{3}$ and Wanhyung $\mathrm{LEE}^{4 *}$ \\ ${ }^{1}$ Biomedical Prediction Technology Laboratory, Korea Institute of Science and Technology \\ Information, Korea \\ ${ }^{2}$ Center for Convergent Research of Emerging Virus Infection, Korea Research Institute of \\ Chemical Technology, Korea \\ ${ }^{3}$ Department of Preventive Medicine, Yonsei University College of Medicine, Korea \\ ${ }^{4}$ Department of Occupational and Environmental Medicine, Gil Medical Center, Gachon \\ University College of Medicine, Korea
}

Received August 23, 2018 and accepted August 1, 2019

Published online in J-STAGE September 13, 2019

\begin{abstract}
The modified International Standard Classification of Occupations (ISCO) has been used empirically to report or investigate working conditions or worker status. We used principal component analysis and k-means clustering to analyze the working population based on 67 occupational characteristics among 23,060 workers from the fourth Korean Working Conditions Survey in 2014. The three-cluster approach classified workers into major groups 1-4 (managers, professionals, technicians, and clerical support workers), 5-6 (service, sales, agricultural, forestry, and fishery workers), and 7-9 (crafts, trades, machine operators, assemblers, and elementary occupations) based on the ISCO-08. The results of the current study suggest a well-defined clustered occupational classification that can be used to report or investigate workers.
\end{abstract}

Key words: Workers, Occupation, Classification, Clustering analysis, Principal component analysis, Korea, International Standard Classification of Occupations, Korean Working Conditions Survey

\section{Introduction}

Occupations are the major means by which most people earn a living. Occupations are also linked to socioeconomic position, satisfaction or achievement in life, and health status (including daily physical activity, eating habits, a seden-

*To whom correspondence should be addressed.

E-mail: wanhyung@gmail.com

(C)2020 National Institute of Occupational Safety and Health tary lifestyle, and exposure to hazards) and are, therefore, an important factor in individuals' lives ${ }^{1,2)}$. Furthermore, workers with the same classification of occupation are likely to have similar lifestyles and behavioral characteristics due to similar working environments ${ }^{3}$. Occupational classification plays an important role in addressing the issues of the working population. Moreover, worldwide industrialization and globalization have increased the demand for a new international standard for occupations to facilitate the collection and reporting of related data. 
The need for an internationally sharable standard of occupation information was first proposed in 1921. In 1958, the International Labour Organization (ILO) created the International Standard Classification of Occupations (ISCO-58) based on three levels of major, minor, and unit groups $^{4)}$. Following its creation, the ISCO-58 was revised several times (ISCO-68, ISCO-88, and ISCO-08). The current revision is the ISCO-08, which classifies occupations into 10 major, 43 sub-major, 130 minor, and 436 unit groups. At present, the ISCO is the standard categorization most commonly used worldwide for reporting and comparing occupational information data. The ISCO uses a framework for classified occupations based on two main concepts: job (tasks and duties) and skill (skill level and skill specialization) (more detailed information is available at http://www.ilo.org/public/english/bureau/stat/isco/ isco08/index.htm).

However, changing occupational characteristics have recently challenged occupational classification based on the similarity of tasks, duties, and skills. For example, working conditions (working hours, schedules, or internetbased work) and work environment (safety, health, or interpersonal networks in the workplace) are important factors that affect occupational characteristics ${ }^{5-7)}$. Furthermore, to date, it is hard to directly apply the ISCO to small-sized studies of working populations or to report partial data on working populations due to the at least 10 major classes included in the ISCO. Therefore, occupational professionals have reported occupational data using their own modified classification of occupations, such as manual/non-manual, white-/blue-collar, office/outdoor, or knowledge/physical workers ${ }^{8-11)}$.

Therefore, this study applied an automated, data-driven approach to classify occupations based on machine learning techniques using data from the fourth Korean Working Conditions Survey (KWCS) in 2014, a nationally representative survey of the working population containing a large number of samples.

\section{Methods}

\section{Study population}

This study used data from the fourth KWCS in 2014, which was conducted in an economically active population aged $15 \mathrm{yr}$ or over who were either employees or self-employed at the time of the interview. The KWCS methodology and survey questionnaire were developed by the Occupational Safety and Health Research Institute in Korea based on the European Working Conditions
Survey ${ }^{12)}$. A total of 50,007 participants responded to the questionnaire. The aim of the KWCS was to identify the rates and causes of work-related diseases and accidents and to verify the effects of mechanical, physical, and chemical hazards in the workplace and psychosocial factors that influenced working conditions ${ }^{13)}$. The participants were interviewed by trained personnel after providing written informed consent. After excluding subjects with missing data, 23,060 individuals were finally included.

\section{The International Standard Classification of Occupations and occupational characteristics}

The recently revised ISCO-08 comprises the following 10 major groups: Major Group 1, legislators, senior officials, and managers; Major Group 2, professionals; Major Group 3, technicians and associate professionals; Major Group 4, clerical support workers; Major Group 5, service and sales workers; Major Group 6, skilled agricultural, forestry, and fishery workers; Major Group 7, craft and related trade workers; Major Group 8, plant and machine operators and assemblers; Major Group 9, elementary occupations; and Major Group 0, armed forces occupations. Because the Republic of Korea has assigned a minimum of 20 months of mandatory military duty to all male citizens (approximately 20-24 yr of age), we used only nine major groups for comparison with other countries, excluding Major Group 0 because of its heterogeneity in age and gender (more detailed information can be found at https:// www.ilo.org/public/english/bureau/stat/isco/isco08/index. $\mathrm{htm})$.

The KWCS included various variables related to occupations, work, or jobs. Initially, we reviewed previous research that reported the characteristics of occupations in the scope of medical, social, policy, and economic science. The KWCS comprised three categories of survey questions: basic worker characteristics (job, type of work, wage, etc.), working conditions (work hours; work schedule; exposure to noise, vibration, dust, or weight; self-rated satisfaction with work, etc.), and the organization and circumstance of the work (union, management, coworkers, bullying or violence in the workplace, etc.). Then, we selected 68 occupational variables related to the occupational characteristics from the KWCS. We performed a principal components analysis with these 68 variables to define 17 principal components each of which included a subset of the original features. Principal components analysis is used for dimensionality reduction and to address multicollinearity problems in experimental data. The components are linear combinations of the original variables that 
are constructed so that each component has a correlation of zero with each of the other components. Each principal component is associated with an eigenvalue. Each eigenvalue represents the total amount of variance explained by its principal component, standardized so that the mean eigenvalue is one. The sum of eigenvalues is equal to the total number of principal components created (which in turn is equal to the total number of input variables) ${ }^{14)}$. Therefore, an eigenvalue $>1$ implies that the principal component explains more of the total variance than the typical input variable or is more useful in the analysis than the mean input variable. We retained any principal component with an eigenvalue $\geq 1$ and discarded those with eigenvalues $<1$. We calculated components scores for 17 principal components of the covariance matrix except for principal components less than the threshold after varimax rotation (orthogonal), which was applied to simplify the interpretation of the principal components (Tables 1-3).

The labels for the 17 component scores indicate the groups of variables with the highest proportion in each principal component. The 68 selected occupational variables were categorized into three groups comprising occupational hazard, working status, and occupational mentality factors. The occupational hazard factors included traditional risk exposures (organic solvent, infection, chemicals, second-hand smoke in the workplace, dust, noise, high/low temperatures, and vibration), ergonomic risk exposure (repetitive movements, fatiguing or painful positions, standing, carrying or moving, and temperature), sedentary lifestyle (working with computers and using the Internet/email for professional purposes), and personal interaction (angry clients, customers, passengers, and patients). The working status factors were largely composed of long working hours (weekly working hours/days and holiday work), regularity (same number of working hours every day or week), complicated work schedule, and long commuting time. The occupational mentality factors included networks in the workplace (support from colleagues or manager), value of work (feeling of work well done and doing useful work), work autonomy, emotional aspects, independence of work, goal-setting by others (pace of work depend on automatic speed of a machine or movement of a product), tight working standard (working at high speed and working to tight deadlines), challenge level of work (monotonous or complex tasks), and demands or interruption from others.

\section{Statistical analysis}

Data were reported as the means \pm standard deviation for continuous variables and as numbers and percentages for categorical variables. $K$-means clustering was performed to group the participants based on the various characteristics. This clustering aims to partition $\mathrm{n}$ observations into $k$ clusters in which each observation belongs to the cluster with the nearest mean. The nearest mean is assigned to each observation in the cluster whose mean has the least squared Euclidean distance as a measure of distance $^{15)}$. For continuous variables, Euclidean distance was used as a distance metric. For dichotomous variables, the simple matching coefficient was adapted for use as a distance metric. In this study, analyses were conducted for two, three, and four categorized clusters. Each clustering group categorized by the k-means technique was compared to the ISCO. The best cluster solution was chosen based on the ease of interpretation of the clusters of the solution. The results of the clustering were compared to the percentage of individuals in an ISCO group that fell into each cluster. All statistical tests were two-tailed and performed using IBM SPSS Statistics for Windows, version 20.0 (IBM Corp., Armonk, NY). $P$-values $<0.05$ were considered statistically significant. We used MATLAB 2012a (Mathworks Inc., Natick, MA, USA) to perform the $k$-means clustering.

\section{Results}

Tables 1-3 show the results of the 17 component scores with detailed information. The 68 occupational variables were categorized with their various patterns and compressed into 17 variables. In these 17 principal components, negative values indicated a response of 'agree' or 'yes' to the question.

Figures 1-3 show the significant differences in dominant clusters according to the Major Groups of the ISCO. In Fig. 1, the two-cluster solution (A2 and B2) showed high proportions of participants in Major Groups 1, 2, 3, 4,7 , and 8 in A2 and higher frequencies of Major Groups 5, 6, and 9 in B2. In Fig. 2, the three-cluster solution (A3, B3, and C3) included Major Groups 1, 2, 3, and 4 in A3; Major Groups 7, 8, and 9 in B3; and Major Groups 5 and 6 in C3. Lastly, in Fig. 3, the four-cluster solution (A4, B4, C4, and D4) included Major Groups 1, 2, 3, and 4 in A4; Major Groups 7 and 8 in B4; Major Group 6 in C4; Major Groups 5 and 9 in D4. After four-cluster solution, there were no significant differences in clusters (Results are not presented).

The three-cluster solution showed significant differences between the first and second-ranked proportions in 
Table 1. Eigenvectors for the principal components with varimax rotation for each occupational hazard

\begin{tabular}{|c|c|}
\hline Characteristics & Eigenvector \\
\hline \multicolumn{2}{|l|}{ Traditional risk exposure } \\
\hline Breathing in vapors such as solvents and thinners & 0.848 \\
\hline Handling or direct contact with potentially infectious materials such as waste, bodily fluids, laboratory materials, etc. & 0.807 \\
\hline Handling or skin contact with chemical products or substances & 0.804 \\
\hline Tobacco smoke from other people & 0.701 \\
\hline Breathing in smoke, fumes (such as welding or exhaust fumes), powder or dust (such as wood dust or mineral dust), etc. & 0.670 \\
\hline Noise so loud that you have to raise your voice to speak & 0.566 \\
\hline Low temperatures (indoors or outdoors) & 0.545 \\
\hline Vibrations from hand tools, machinery, etc. & 0.540 \\
\hline \multicolumn{2}{|l|}{ Ergonomic risk exposure } \\
\hline Repetitive hand or arm movements & 0.716 \\
\hline Tiring or painful positions & 0.700 \\
\hline Standing & 0.600 \\
\hline Carrying or moving heavy loads & 0.583 \\
\hline High temperatures that make you perspire even when not working & 0.569 \\
\hline Does your job ever require you to wear personal protective equipment? & 0.390 \\
\hline \multicolumn{2}{|l|}{ Sedentary lifestyle } \\
\hline Using the Internet/email for professional purposes & 0.932 \\
\hline Working with computers: PCs, networks, mainframes & 0.929 \\
\hline \multicolumn{2}{|l|}{ Personal interaction } \\
\hline Handling angry clients & 0.766 \\
\hline Dealing directly with people who are not employees at your workplace such as customers, passengers, pupils, patients, etc. & 0.726 \\
\hline Lifting or moving people & 0.531 \\
\hline
\end{tabular}

Table 2. Eigenvectors for the principal components with varimax rotation for working status

\begin{tabular}{lc}
\hline \multicolumn{1}{c}{ Characteristics } & Eigenvector \\
\hline Long working hours & 0.831 \\
How many hours do you usually work per week in your main paid job? & 0.813 \\
How many times per month do you work more than 10 hours per day? & 0.778 \\
How many times per month do you work in the evening, for at least two hours between 6:00 pm and 10:00 pm? & 0.669 \\
How many days per week do you usually work in your main paid job? & 0.650 \\
How many times per month do you work on Saturdays? & 0.556 \\
In general, do your working hours fit in with your family or social commitments outside work very well, well, not very well, \\
or not at all well? \\
How many times per month do you work on Sundays? \\
Regularity \\
The same number of hours every week \\
The same number of hours every day \\
The same number of days every week \\
Fixed starting and finishing times \\
Complicated work schedule \\
Shifts \\
Normally, how many times per month do you work at night, for at least two hours between 10:00 pm and 05:00 am? \\
On call \\
Long commuting time \\
In total, how many minutes per day do you usually spend traveling from home to work and back? \\
\hline
\end{tabular}


Table 3. Eigenvectors for the principal components with varimax rotation for occupational mental status

\begin{tabular}{|c|c|}
\hline Characteristics & Eigenvector \\
\hline \multicolumn{2}{|l|}{ Networks in the workplace } \\
\hline You are consulted before targets are set for your work & 0.920 \\
\hline Your manager helps and supports you & 0.907 \\
\hline You are involved in improving the work organization or work processes of your department or organization & 0.905 \\
\hline Your colleagues help and support you & 0.865 \\
\hline You have a say in the choice of your working partners & 0.755 \\
\hline The direct control of your pace of work is dependent on your manager & 0.590 \\
\hline \multicolumn{2}{|l|}{ Value of work } \\
\hline Your job gives you the feeling of work well done & 0.763 \\
\hline You are able to apply your own ideas in your work & 0.737 \\
\hline You have the feeling of doing useful work & 0.726 \\
\hline You know what is expected of you at work & 0.713 \\
\hline You have enough time to get the job done & 0.692 \\
\hline You can take a break when you wish & 0.548 \\
\hline You can influence decisions that are important for your work & 0.524 \\
\hline \multicolumn{2}{|l|}{ Autonomy of work } \\
\hline Are you able to choose or change your methods of work? & 0.930 \\
\hline Are you able to choose or change your order of tasks? & 0.919 \\
\hline Are you able to choose or change your speed or rate of work? & 0.891 \\
\hline \multicolumn{2}{|l|}{ Emotional aspects } \\
\hline You get emotionally involved in your work & 0.791 \\
\hline You experience stress in your work & 0.682 \\
\hline You are able to apply your own ideas in your work & 0.680 \\
\hline Your job requires you to hide your feelings & 0.643 \\
\hline \multicolumn{2}{|l|}{ Independence of work } \\
\hline Assessing the quality of your work yourself & 0.831 \\
\hline Solving unforeseen problems on your own & 0.794 \\
\hline Meeting precise quality standards & 0.523 \\
\hline \multicolumn{2}{|l|}{ Goal-setting by others } \\
\hline Your pace of work is dependent on the automatic speed of a machine or movement of a product & 0.829 \\
\hline Your pace of work is dependent on numerical production targets or performance targets & 0.780 \\
\hline Your pace of work is dependent on the work done by colleagues & 0.567 \\
\hline \multicolumn{2}{|l|}{ Tight working standards } \\
\hline Working at very high speed & 0.902 \\
\hline Working to tight deadlines & 0.887 \\
\hline \multicolumn{2}{|l|}{ Challenge level of work } \\
\hline Monotonous tasks & 0.830 \\
\hline Complex tasks & 0.801 \\
\hline Learning new things & 0.532 \\
\hline \multicolumn{2}{|l|}{ Demands or interruption from others } \\
\hline Your pace of work is dependent on direct demands from people such as customers, passengers, pupils, patients, etc. & 0.650 \\
\hline How often do you have to interrupt a task you are doing in order to take on an unforeseen task? & 0.466 \\
\hline
\end{tabular}

each of the ISCO Major Groups. The average percentage of the dominant clusters (A3 in Major Groups 1, 2, 3, and 4; B3 in Major Groups 7, 8, and 9; and C3 in Major Groups 5 and 6 ) was $71.2 \%$. The average percentage of the second-highest clusters (A3 in Major Group 5, B3 in Major Groups 3, 4, and 6; and C3 in Major Groups 1, 2,
7,8 , and 9) was $18.9 \%$ ( $p<0.0001$ in all ISCO groups). Furthermore, the sum of squared means from the results of $k$-means clustering was significantly lower in the threecluster solution by trend curve analysis (graph not shown). Therefore, we selected the three-clusters solution for the current analysis of the compact occupational classification. 


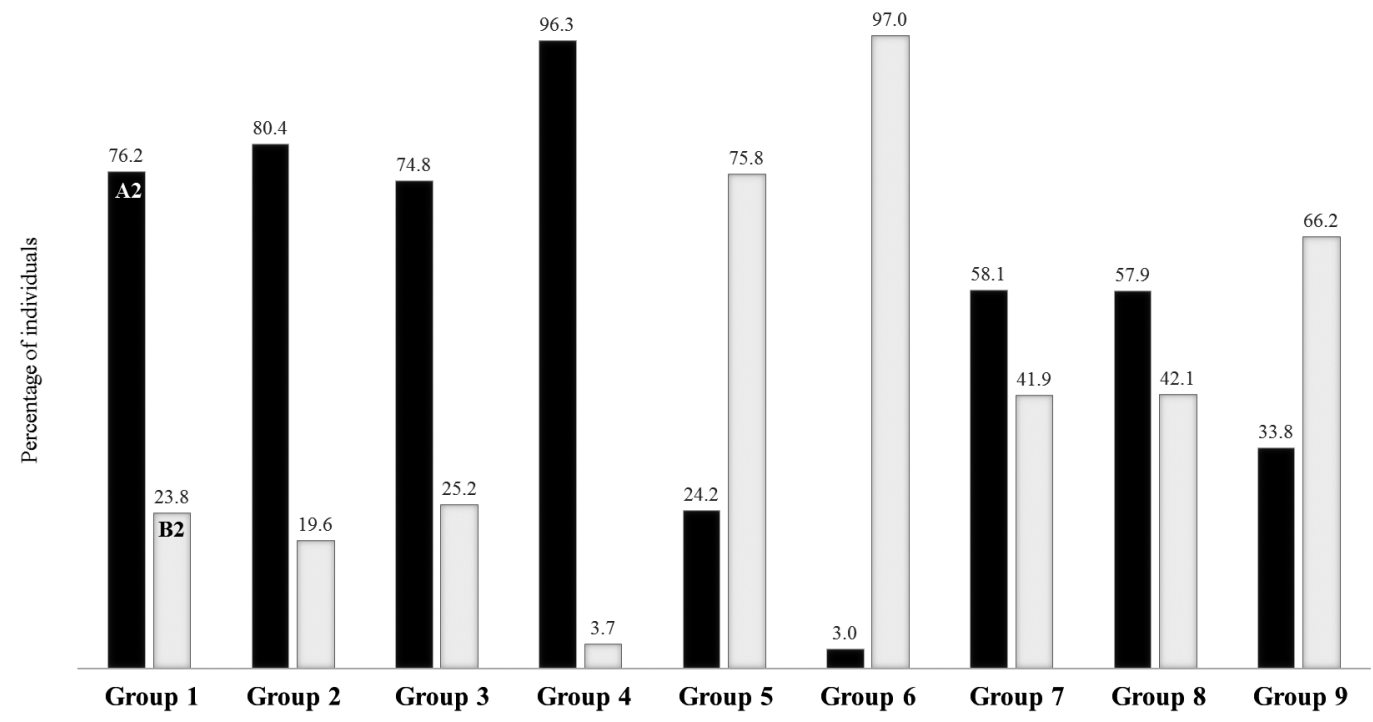

Fig. 1. Proportions of individuals from the Korean Working Conditions Survey in two-cluster clustering (A2 and B2) according to the major groups of the International Standard Classification of Occupations.

Group $1(\mathrm{~N}=558)$ : Managers, Group $2(\mathrm{~N}=1,917)$ : Professionals, Group $3(\mathrm{~N}=1,120)$ : Technicians and associate professionals, Group 4 (N=5,337): Clerical support workers, Group 5 ( $\mathrm{N}=8,233)$ : Service and sales workers, Group $6(\mathrm{~N}=641)$ : Skilled agricultural, forestry and fishery workers, Group $7(\mathrm{~N}=2,223)$ : Craft and related trades workers, Group $8(\mathrm{~N}=1,428)$ : Plant and machine operators, and assemblers, and Group $9(\mathrm{~N}=1,603)$ : Elementary occupations.

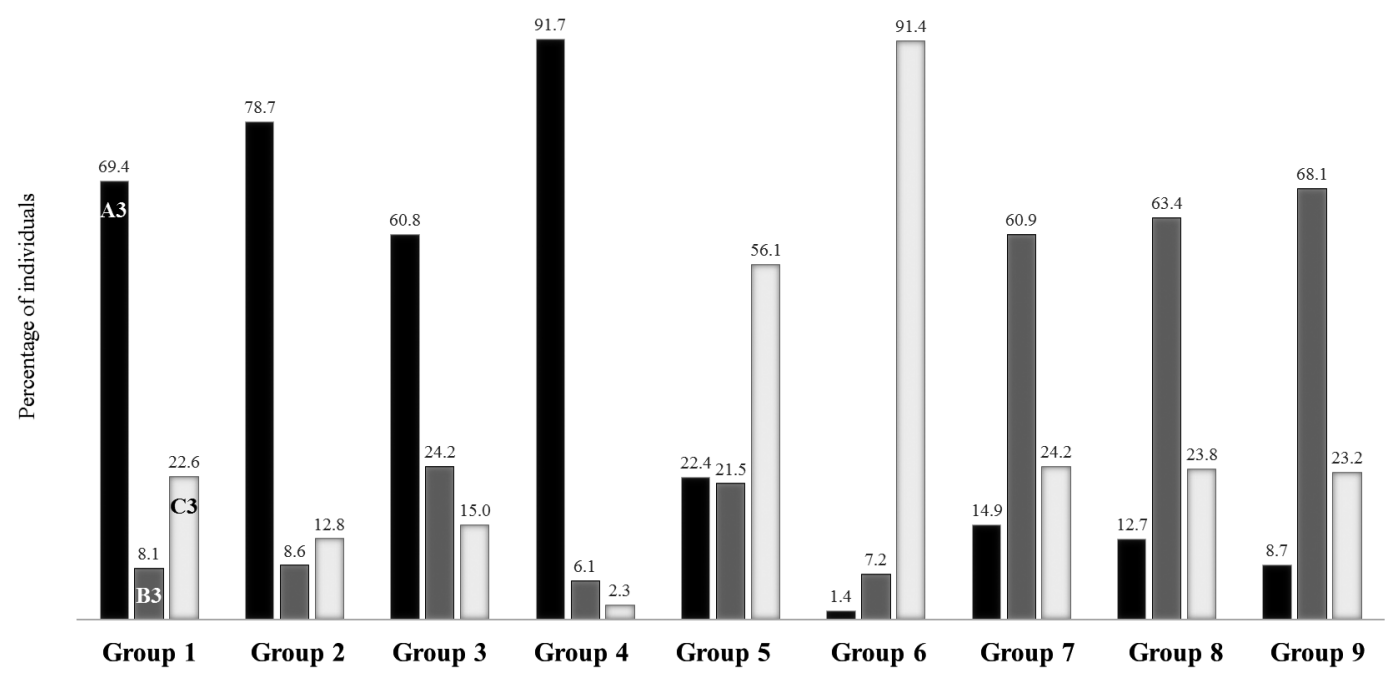

Fig. 2. Proportions of individuals from the Korean Working Conditions Survey in the three-cluster clustering (A3, B3, and C3) according to the major groups of the International Standard Classification of Occupations.

Group $1(\mathrm{~N}=558)$ : Managers, Group $2(\mathrm{~N}=1,917)$ : Professionals, Group $3(\mathrm{~N}=1,120)$ : Technicians and associate professionals, Group 4 (N=5,337): Clerical support workers, Group 5 ( $\mathrm{N}=8,233)$ : Service and sales workers, Group $6(\mathrm{~N}=641)$ : Skilled agricultural, forestry and fishery workers, Group 7 (N=2,223): Craft and related trades workers, Group $8(\mathrm{~N}=1,428)$ : Plant and machine operators, and assemblers, and Group $9(\mathrm{~N}=1,603)$ : Elementary occupations.

Table 4 shows the results of three categories obtained by $k$-means clustering of the occupational characteristics. The values are the means of the component scores of people in each cluster. Group A3 was characterized by a sedentary lifestyle, work independence, and high challenging work. The pace of work in this group was not influenced by direct demands from others or by interruptions. Group B3 was characterized by personal interaction with long work- 


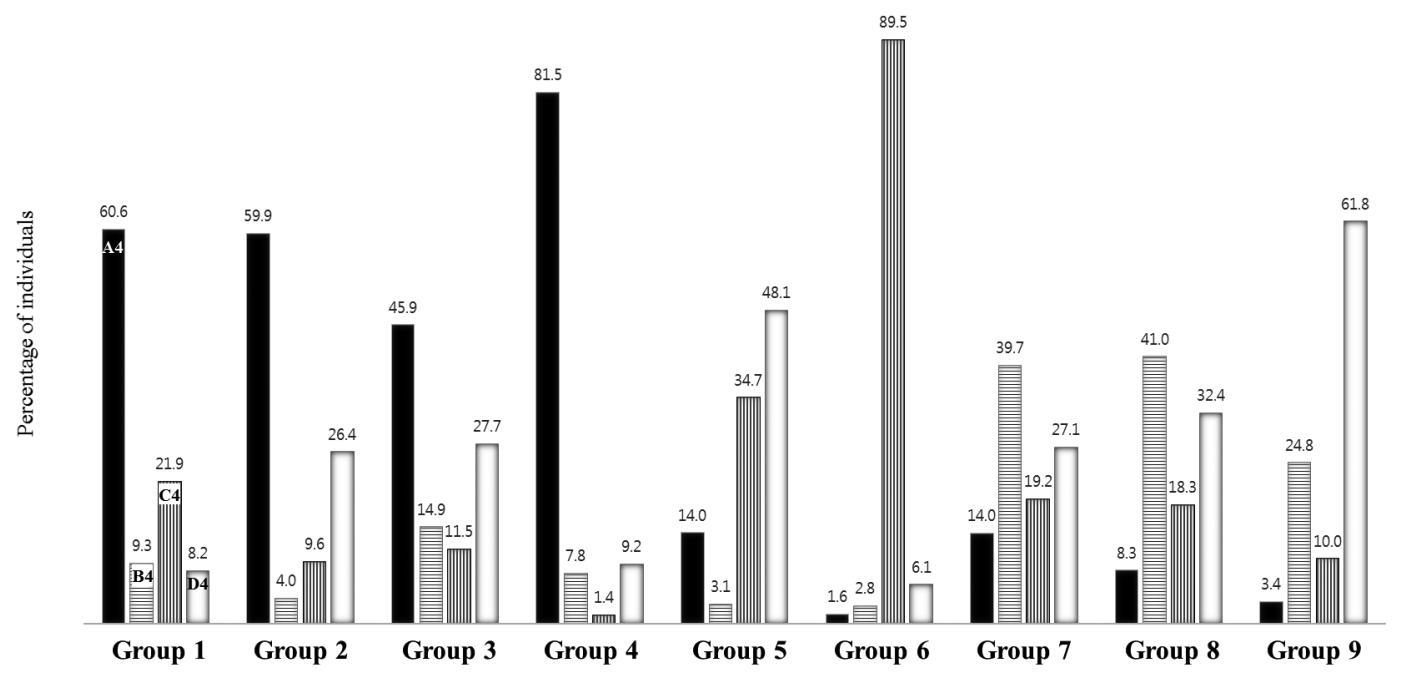

Fig. 3. Proportions of individuals from the Korean Working Conditions Survey in the four-cluster clustering (A4, B4, C4, and D4) according to the major groups of the International Standard Classification of Occupations.

Group 1 (N=558): Managers, Group 2 ( $\mathrm{N=1,917):} \mathrm{Professionals,} \mathrm{Group} 3(\mathrm{~N}=1,120)$ : Technicians and associate professionals, Group 4 ( $\mathrm{N}=5,337)$ : Clerical support workers, Group 5 ( $\mathrm{N}=8,233)$ : Service and sales workers, Group $6(\mathrm{~N}=641)$ : Skilled agricultural, forestry and fishery workers, Group $7(\mathrm{~N}=2,223)$ : Craft and related trades workers, Group $8(\mathrm{~N}=1,428)$ : Plant and machine operators, and assemblers, and Group $9(\mathrm{~N}=1,603)$ : Elementary occupations.

Table 4. Results of triple clustering according to occupational characteristics (k-mean/standard deviation)

\begin{tabular}{lccc}
\hline \multicolumn{1}{c}{ Characteristics } & \multicolumn{2}{c}{ Three clusters } \\
\cline { 2 - 4 } & A3 & B3 & C3 \\
\hline Occupational hazard factors & $0.14(0.77)$ & $0.09(0.95)$ & $-0.35(1.28)$ \\
$\quad$ Traditional risk exposure & $0.44(0.70)$ & $0.05(0.87)$ & $-0.79(1.09)$ \\
Ergonomic risk exposure & $-0.64(0.97)$ & $0.59(0.65)$ & $0.36(0.75)$ \\
Sedentary lifestyle & $0.09(0.88)$ & $-0.32(0.96)$ & $0.23(1.14)$ \\
Personal interaction & & & \\
Working status factors & $0.43(0.60)$ & $-0.73(1.14)$ & $0.15(0.86)$ \\
Long working hours & $-0.22(0.74)$ & $0.37(1.23)$ & $-0.07(0.94)$ \\
Regularity & $0.23(0.53)$ & $0.20(0.76)$ & $-0.63(1.48)$ \\
Complicated work schedule & $-0.37(1.00)$ & $0.53(0.81)$ & $-0.01(0.93)$ \\
Long commuting time & & & \\
Occupational mentality factors & $-0.53(0.50)$ & $1.01(1.08)$ & $-0.32(0.49)$ \\
Networks in the workplace & $-0.14(0.91)$ & $-0.13(1.10)$ & $0.38(0.92)$ \\
Value of work & $0.00(1.00)$ & $-0.09(1.00)$ & $0.12(0.98)$ \\
Autonomy of work & $-0.06(1.02)$ & $-0.07(0.97)$ & $0.19(0.98)$ \\
Emotional aspects & $-0.02(1.01)$ & $0.01(1.01)$ & $0.02(0.96)$ \\
Independence of work & $0.17(0.81)$ & $0.27(0.47)$ & $-0.60(1.42)$ \\
Goal-setting by others & $0.24(0.85)$ & $0.06(0.94)$ & $-0.47(1.13)$ \\
Tight working standards & $-0.38(0.95)$ & $0.24(0.92)$ & $0.36(0.94)$ \\
Challenge level of work & $0.07(0.98)$ & $-0.01(1.01)$ & $-0.11(1.01)$ \\
Demands or interruption from others & & &
\end{tabular}

Negative values indicate an 'agree' or 'yes' response to the question.

ing hours, irregular working schedule, short commuting time, no network in the workplace, and autonomy of work. Group C3 group traditional and ergonomic risk exposures, complicated working schedules, poor value placed on work, worse emotional aspects than other groups, goalsetting by others, and tight working standards. 


\section{Discussion}

The current study was a first attempt to investigate the association between the ISCO and occupational characteristics using clustered data from a large-scale, nationally representative survey of a working population. The results of this study suggest one definition of an occupational coding system. We selected a three-cluster occupational classification system based on the major groups of the ISCO. Other studies have also empirically used the threegroup classification of work similar to the three clusters proposed by our study, such as office, non-manual; whitecollared workers/outdoor, manual; or blue-collared workers/other classifications. In the present study, group A3 included ISCO-08 Major Groups 1-4, which are commonly referred to as office, non-manual, or white-collared workers. Group B3 included the ISCO-08 Major Groups $7-9$, which are commonly referred to as outdoor, manual, or blue-collared workers. Finally, group $\mathrm{C} 3$ included the ISCO-08 Major Groups 5 and 6, which include service or sales and agricultural, forestry, and fishery workers. Considering the current study's results of a three-cluster system using various occupational factors and the empirical use by occupational professions, the three-cluster system of occupations is recommended for analysis, reporting, or investigation.

The results of the $k$-means clustering were based on numerous occupational characteristics including occupational hazard factors, working status, and job-related mental aspects. The ILO categorized occupations according to job tasks, duties, and skills ${ }^{16)}$. However, the workplace environment, working conditions, and the concept of a job have rapidly changed and more people are working in various places. Therefore, there is a need to address various occupational factors and working conditions using a standard occupational classification. We performed $k$-means clustering using various occupational characteristics, some of which were handled as conceptually key aspects to classify the occupations. Adam Smith indicated the importance of the working environment (including hazardous factors or work), regularity of work, and responsibility to perform tasks. ${ }^{17}$

Recently, occupational characteristics have changed rapidly since the ILO built ISCO. According to a World Health Organization report ${ }^{18)}$, almost 2.9 billion workers worldwide are exposed to hazards in their workplace, including chemical hazards, toxic substances, airborne particulates, noise, ergonomic stressors (standing, handling loads, fixed positions, and repeated movement), and risk factors for injuries. Furthermore, some workers currently sit at a desk while working with computers or on the Internet, whereas other workers are frequently required to meet customers face-to-face to achieve their goals or to solve customers' complaints ${ }^{19)}$. The worldwide economy is increasingly based on market globalization and online commerce. Therefore, the workplace environment has changed rapidly and more people are working longer hours (including commuting time) and are employed in various types of work schedules. As a result, work schedules and the type of work have become more important to the employment status of working populations ${ }^{20)}$. Workers' perceptions and interactions with colleagues in the workplace or the organization influence both work and life ${ }^{21)}$. In addition, the manifestations of the job are related to the perceptions of job resources (autonomy, value, supervisory coaching, independence of performing tasks, or the psychological climate of cooperation and warmth) $)^{21,22)}$.

According to the results of the current investigation, workers in group A3 worked on the Internet or computers for professional purposes and had regular working schedules and long commuting times. They worked with colleagues or partners in closed networks. Furthermore, they placed a high value on their work. They experienced excess of the stress in the workplace due to their emotional involvement in their tasks. However, they had work autonomy and independence. Workers in group B3 mostly did not work with coworkers but rather with customers, passengers, pupils, or patients. They worked longer hours and were emotionally involved in their tasks. As with worker in A3, They had a highly value work and have autonomy with working too such as workers in A3 group. Workers in group C3 worked with occupationally hazardous environments with exposure to chemicals, smoke, dust, heavy loads, repetitive movement, noise, or vibration.

A major limitation of this study is the study population. We used data from a large-scale, nationally representative survey of the working population of Korea in Asia. However, social climates and working environments differ depending on the nation or people. Multinational studies are needed to better understand how to set an international classification of occupations. Because the consideration of various occupational characteristics in the clustering of occupations did not completely classify the workers in the present study, our results should be interpreted with caution. We should focus on minor classes of workers to investigate the working population. Moreover, we clustered based only on occupational characteristics. Future studies should consider clustering based on other factors such as 
chemical exposures, diseases, etc. to understand how occupational groupings may change based on such features. The results of the current study cannot be extrapolated to all working conditions or countries. These findings are based on experimental and conceptual analysis and cannot be applied directly to workplaces without further analysis or international data. These results also describe occupational characteristics based on occupational classification (not industrial classification) only at an ecological level due to the lack of scope at the individual level. These results therefore need to be population and occupational classification based interpreted.

Finally, this study was based on an ecological study design. A much-debated question remains regarding whether to set a boundary for occupational classification-related factors. We could not include all potential characteristics related to occupational classification due to the nature of the data from the KWCS. There is, however, a definite need for international occupational classification including various workers' statuses and working conditions. The results of the present study suggest that an occupational classification comprising three clusters reflects various occupational characteristics. Future studies will help us to establish increased accuracy in occupational classification.

The main goal of the current study was to suggest a well-defined clustered occupational classification with various occupational characteristics according to the ISCO-08. The three-cluster solution significantly classified workers, such as Major Groups 1-4 (white-collared workers), 5-6 (service, sales, agricultural, forestry, and fishery workers), and 7-9 (blue-collared workers) of the ISCO-08. The results of this study have raised questions about the occupational classifications used to report data on workers or to study workers, which warrant further investigation.

\section{Conflict of Interest}

The authors declare no conflicts of interest.

\section{Acknowledgment}

The authors thank the participants of the KWCS for the opportunity to perform this research.

\section{References}

1) Winkleby MA, Jatulis DE, Frank E, Fortmann SP (1992) Socioeconomic status and health: how education, income, and occupation contribute to risk factors for cardiovascular disease. Am J Public Health 82, 816-20. [Medline] [CrossRef]

2) Riise T, Moen BE, Nortvedt MW (2003) Occupation, lifestyle factors and health-related quality of life: the Hordaland Health Study. J Occup Environ Med 45, 324-32. [Medline] [CrossRef]

3) Weeden KA, Grusky DB (2005) The Case for a new class map. Am J Sociol 111, 141-212. [CrossRef]

4) Ganzeboom HBG, Treiman DJ (1996) Internationally comparable measures of occupational status for the 1988 International Standard Classification of Occupations. Soc Sci Res 25, 201-39. [CrossRef]

5) Kilbourne B, England P, Beron K (1994) Effects of individual, occupational, and industrial characteristics on earnings: intersections of race and gender. Soc Forces 72, 1149-76. [CrossRef]

6) De Rijk A, Nijhuis F, Alexanderson K (2009) Gender differences in work modifications and changed job characteristics during the return-to-work process: a prospective cohort study. J Occup Rehabil 19, 185-93. [Medline] [CrossRef]

7) Goldberg M, Chastang JF, Leclerc A, Zins M, Bonenfant S, Bugel I, Kaniewski N, Schmaus A, Niedhammer I, Piciotti M, Chevalier A, Godard C, Imbernon E (2001) Socioeconomic, demographic, occupational, and health factors associated with participation in a long-term epidemiologic survey: a prospective study of the French GAZEL cohort and its target population. Am J Epidemiol 154, 373-84. [Medline] [CrossRef]

8) Neal AG, Rettig S (1963) Dimensions of alienation among manual and non-manual workers. Am Sociol Rev 28, 599-608. [CrossRef]

9) Locke EA (1973) Satisfiers and dissatisfiers among whitecollar and blue-collar employees. J Appl Psychol 58, 67-76. [CrossRef]

10) Vågero D, Ringbäck G, Kiviranta H (1986) Melanoma and other tumors of the skin among office, other indoor and outdoor workers in Sweden 1961-1979. Br J Cancer 53, 507-12. [Medline] [CrossRef]

11) Dul J, Ceylan C, Jaspers F (2011) Knowledge workers' creativity and the role of the physical work environment. Hum Resour Manage 50, 715-34. [CrossRef]

12) Park JB, Nakata A, Swanson NG, Chun H (2013) Organizational factors associated with work-related sleep problems in a nationally representative sample of Korean workers. Int Arch Occup Environ Health 86, 211-22. [Medline] [CrossRef]

13) Jeon SH, Leem JH, Park SG, Heo YS, Lee BJ, Moon SH, Jung DY, Kim HC (2014) Association among working hours, occupational stress, and presenteeism among wage workers: results from the Second Korean Working Conditions Survey. Ann Occup Environ Med 26, 6. [Medline] [CrossRef]

14) Sheean PM, Bruemmer B, Gleason P, Harris J, Boushey C, 
Van Horn L (2011) Publishing nutrition research: a review of multivariate techniques-part 1. J Am Diet Assoc 111, 103-10. [Medline] [CrossRef]

15) Risvas G, Panagiotakos DB, Chrysanthopoulou S, Karasouli K, Matalas AL, Zampelas A (2008) Factors associated with food choices among Greek primary school students: a cluster analysis in the ELPYDES study. J Public Health (Oxf) 30, 266-73. [Medline] [CrossRef]

16) The International Standard Classification of Occupations Introduction to occupational classifications. 2004. http:// www.ilo.org/public/english/bureau/stat/isco/intro.htm. Accessed March 26, 2018.

17) Fry M (2005) Adam Smith's Legacy: his place in the development of modern economics. Taylor \& Francis, London.

18) Ezzati M, Lopez AD, Rodgers A, Murray CJL (2004) Comparative quantification of health risks: global and regional burden of disease attributable to selected major risk factors. Geneva, 1651-801.

19) Lim SS, Lee W, Hong K, Jeung D, Chang SJ, Yoon JH (2016) Facing complaining customer and suppressed emotion at worksite related to sleep disturbance in Korea. J Korean Med Sci 31, 1696-702. [Medline] [CrossRef]

20) Peters V, Engels JA, de Rijk AE, Nijhuis FJ (2015) Sustainable employability in shiftwork: related to types of work schedule rather than age. Int Arch Occup Environ Health 88, 881-93. [Medline] [CrossRef]

21) Hombrados-Mendieta I, Cosano-Rivas F (2013) Burnout, workplace support, job satisfaction and life satisfaction among social workers in Spain: a structural equation model. Int Soc Work 56, 228-46. [CrossRef]

22) Xanthopoulou D, Bakker AB, Demerouti E, Schaufeli WB (2009) Reciprocal relationships between job resources, personal resources, and work engagement. J Vocat Behav 74, 235-44. [CrossRef] 